\title{
Environmental and cognitive correlates of adolescent breakfast consumption
}

\author{
Cara S. DeJong *, Frank J. van Lenthe, Klazine van der Horst, Anke Oenema \\ Department of Public Health, Erasmus University Medical Center, Rotterdam, The Netherlands
}

\section{A R T I C L E I N F O}

Available online 13 February 2009

Keywords:

Environment

Cognitive

Breakfast

Adolescent

Theory of planned behavior

Mediation

\section{A B S T R A C T}

Objective. This study aimed to identify cognitive and environmental correlates of daily adolescent breakfast consumption.

Methods. Adolescents ( $n=1089$ ) aged $12-15$ years in schools in Rotterdam, The Netherlands, completed a questionnaire measuring daily breakfast consumption, individual cognitions, and home environmental factors during the 2005-2006 school year. Multilevel logistic regression analysis was performed to determine the association between the environmental variables, cognitions and everyday breakfast consumption. Additionally, mediation of the effect of the environmental variables through the individual cognitions on breakfast consumption was explored.

Results. Attitude, perceived behavioral control, modeling by friends and parents, and intention were associated with daily breakfast consumption. Political (breakfast rules), physical (available breakfast products), and socio-cultural (having breakfast with a parent, having the evening meal with a parent, eating the evening meal in front of the TV) environments were also associated with daily breakfast consumption. Associations of the environmental factors were partly mediated by the individual cognitions.

Conclusions. Individual cognitions and a supportive home environment are associated with adolescent breakfast consumption. Since parents primarily shape the home environment, interventions aimed at improving adolescent breakfast consumption should target the parent as well as the adolescent.

(c) 2009 Elsevier Inc. All rights reserved.

\section{Introduction}

Adolescent overweight and obesity rates are rapidly increasing worldwide. Obesity is caused by a long-term imbalance between energy intake and expenditure. Many dietary and physical activity behaviors increase the risk of becoming overweight and obese, one of which is skipping breakfast (Koplan et al., 2005). Prevention of overweight and obesity is recommended to combat this growing public health problem and eating breakfast daily is one of the prevention methods (Koplan et al., 2005; Barlow, 2007). Previous work on adolescent breakfast consumption has primarily focused on the positive nutritional impact of the meal and its association with body weight (Affenito et al., 2005; Rampersaud et al., 2005; Niemeier et al., 2006; Roseman et al., 2007). Children and adolescents who skip breakfast are at increased risk for skipping other meals, snacking, being less physically active and being overweight and obese (Rampersaud et al., 2005; Utter et al., 2007). Known adolescent risk factors for skipping breakfast include being female, dissatisfaction with one's body, aging, and a low socioeconomic status (Videon and Manning, 2003; Rampersaud et al., 2005; Crossman et al., 2006; Larson et al., 2007). The current body of research related to adolescent breakfast consumption provides necessary information about identifying specific risk

\footnotetext{
* Corresponding author. 540 Memorial Drive \#510, Cambridge, MA 02139, USA. E-mail address: youngdejongs@gmail.com (C.S. DeJong).
}

groups to target in interventions, yet little is known about the important and changeable determinants. Identifying these determinants is critical to successful intervention development and therefore the aim of our study was to identify cognitive and environmental correlates of daily adolescent breakfast consumption.

Social-ecological models, such as the Environmental Research Framework for Weight Gain Prevention (EnRG model), postulate that behaviors are determined by factors in the environment and individual cognitions (Kremers et al., 2006). Environmental factors of importance may include the physical environment, the sociocultural environment, the political environment, and the economic environment; and can be divided into the micro-level (such as the household) and the macro-level (such as the government) (Swinburn et al., 1999). According to the EnRG model environmental factors can either have a direct or an indirect effect. An automatic response to an environmental cue that does not need cognitive consideration is a direct effect. An indirect effect on the behavior occurs when the environmental factor is mediated through the individual cognitions. This study included individual cognitions defined by the Theory of Planned Behavior (TPB): intention to perform the behavior, attitude toward the behavior, perceived control over the behavior, and the subjective social norms to perform the behavior (Ajzen, 1991) as well as modeling of the behavior by important others (Bandura, 1971).

Previous social-ecological research on adolescent breakfast consumption has predominantly focused on the socio-cultural environment, demonstrating that "family meals" is a significant determinant 
(Tibbs et al., 2001; Keski-Rahkonen et al., 2003; Videon and Manning, 2003; Brown and Ogden, 2004; Swinburn et al., 2004; Affenito et al., 2005; Kvaavik et al., 2005). Three studies investigating individual cognitions as potential correlates of breakfast consumption have found that perceived difficulty, self efficacy and intention are significant determinants of healthy breakfast food choices in adolescents (Cusatis and Shannon, 1996; Gummeson et al., 1997; Berg et al., 2000). However, the existing research that includes both environmental factors and individual cognitions, and examines mediation pathways is very limited. One known study researched the eating habits of Dutch 13 year olds $(n=203)$ and included both environmental and cognitive correlates of breakfast consumption finding attitude to be the only significant correlate (Martens et al., 2005). Our ecological study aims to augment past work by further investigating adolescent breakfast consumption in a large sample using a broad range of cognitive and environmental variables along with mediation analysis.

The purpose of this study was to: (i) investigate associations of physical, socio-cultural and political environmental correlates and individual cognitions with breakfast consumption, and (ii) determine whether the individual cognitions act as mediators of the association of the environmental correlates and breakfast consumption among adolescents.

\section{Methods}

\section{Study design}

Data for this cross sectional study came from the baseline data of the ENDORSE study: Research into Environmental Determinants of Obesity Related Behaviors in Rotterdam School Children. Details of the ENDORSE study have been reported elsewhere (van der Horst et al., 2008). Students completed a survey questionnaire consisting of the outcome measures, individual cognitions, and environmental questions for numerous obesity related behaviors during school hours. The Medical Ethics Committee of the Erasmus Medical Center issued a declaration of no objection for the ENDORSE study.

\section{Participants and procedure}

Participants were adolescents aged 12-15 years, in Rotterdam schools, The Netherlands. All schools participating in the ongoing Youth Monitoring system of the Municipal Health Services in Rotterdam (YMR) in 2005/2006 were asked to participate in this study ( $n=56$ schools). Twenty four schools were willing to participate and 14 were randomly selected for inclusion. Depending on the school size, 3-6 classes from each school were randomly selected for participation in the study ( $n=1668$ children). Parents were informed of the study through a letter and could decline their child's participation by contacting the teacher. Children with missing self-report data, who were absent, or refused to participate were excluded from the study, leaving 1361 adolescents in our original sample. Respondents who completed less then $80 \%$ of the questionnaire and/or skipped the breakfast consumption and ethnicity questions were not included in the study; the final sample size was $n=1089$. Respondents that were deleted from the original sample were significantly more likely to be in low and middle level education, to be male, and to be of non-Western descent (results not shown).

Table 1

The study survey questions and responses, The Netherlands (2005-2006)

\begin{tabular}{|c|c|c|}
\hline Constructs & Questions & Recoded answers \\
\hline \multicolumn{3}{|l|}{ Outcome measure } \\
\hline $0,1,2,3,4,5$ days & “On how many school days do you usually eat breakfast?” & The responses were summed to determine the total weekly \\
\hline $0,1,2$ days & "On how many weekend days do you usually eat breakfast?" & breakfast consumption: $1=$ everyday, $0=$ not everyday \\
\hline \multicolumn{3}{|l|}{ Theory of planned behavior constructs } \\
\hline \multirow[t]{2}{*}{ Attitude $^{\mathrm{b}}$} & "I think eating breakfast is-" (very good - very bad) & $(+2)-(-2)$ Assessed with two items and a mean score \\
\hline & "I think eating breakfast is-" (very pleasant - very unpleasant) & was used (Chronbach $\alpha=0.80$ ) \\
\hline Subjective norm ${ }^{\mathrm{b}}$ & "If I eat breakfast my parents think it is-" (very good-very bad) & $(+2)-(-2)$ \\
\hline Perceived modeling by parents ${ }^{\mathrm{b}}$ & "How often do parents eat breakfast-" (always-never) & $(+2)-(-2)$ \\
\hline Perceived modeling by friends ${ }^{\mathrm{b}}$ & "How often do friends eat breakfast-" (always-never) & $(+2)-(-2)$ \\
\hline Perceived behavior control ${ }^{\mathrm{b}}$ & $\begin{array}{l}\text { "Do you decide by yourself if you eat breakfast?" (yes, that is } \\
\text { completely my decision" - "no, that is not my own decision) }\end{array}$ & $(+2)-(-2)$ \\
\hline Perceived behavior control $^{\mathrm{b}}$ & $\begin{array}{l}\text { "How easy or difficult is it for you to eat breakfast if you want to?" } \\
\text { (very easy-very difficult) }\end{array}$ & $(+2)-(-2)$ \\
\hline Intention $^{\mathrm{b}}$ & $\begin{array}{l}\text { "Do you intend to eat breakfast in the next six months?" } \\
\text { (surely-surely not) }\end{array}$ & $(+2)-(-2)$ \\
\hline \multicolumn{3}{|l|}{ Environmental factors } \\
\hline Physical availability & $\begin{array}{l}\text { "Are there mostly sufficient breakfast products available at home } \\
\text { to eat breakfast?" (yes, no) }\end{array}$ & $(1),(0)$ \\
\hline The political environment & $\begin{array}{l}\text { "Are there home rules about what you are allowed and not allowed } \\
\text { to eat for breakfast?" (yes }=1, \text { no }=0 \text { ) } \\
\text { "Are there home rules about eating breakfast together } \\
\text { at the table?" (yes }=1, \text { no }=0 \text { ) } \\
\text { "Are there home rules about whether you should eat breakfast?" } \\
\text { (yes }=1, \text { no }=0 \text { ) }\end{array}$ & $\begin{array}{l}\text { A composite score ranging from } 0 \text { to } 3 \text { rules was } \\
\text { computed by summing the three answers. }\end{array}$ \\
\hline Socio-cultural environment & $\begin{array}{l}\text { "How many days per week do you eat breakfast with a parent" } \\
\text { (0-7 days per week) } \\
\text { "How many days per week do you eat the evening meal with } \\
\text { a parent" ( } 0-7 \text { days per week) } \\
\text { "How many days per week do you eat the evening meal in } \\
\text { front of the TV" ( } 0-7 \text { days per week) }\end{array}$ & $\begin{array}{l}\text { Each variable remained separate and each was recoded } \\
\text { into "rarely" }(0-2 \text { days), "sometimes" }(>2<5 \text { days), } \\
\text { "frequently" ( } \geq 5<7 \text { days), "always" ( } 7 \text { days). }\end{array}$ \\
\hline
\end{tabular}

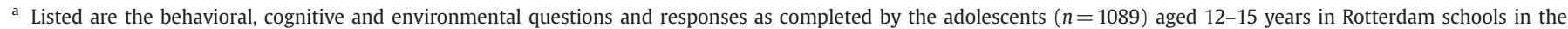
Netherlands during the 2005-2006 school year.

b All TPB constructs were assessed with one item on five-point scales except for Attitude which was assessed with two items and the mean score was used. The most negative answers were coded with -2 , the most positive with +2 . 
Table 2

Baseline characteristics of study population from The Netherlands, 2005-2006 $(N=1089)$

\begin{tabular}{lll}
\hline Characteristics & $N$ & $\%$ \\
\hline Males & 585 & 53.7 \\
Mean age in years (SD) & $14.08+/-(1.19)$ & \\
Ethnicity: Western descent & 552 & 50.7 \\
School level & & \\
$\quad$ University preparation & 335 & 30.8 \\
$\quad$ Higher professional preparation & 153 & 14.0 \\
Vocational preparation & 601 & 55.2 \\
\hline
\end{tabular}

\section{Measurement}

Breakfast consumption was measured by the number of school and weekend days participants ate breakfast (see Table 1 ). The responses were summed to determine the total weekly breakfast consumption and total breakfast consumption was recoded into $0=$ not everyday, and $1=$ everyday.

The TPB constructs attitude, subjective norm, perceived behavior control (decision for self to eat breakfast, ease of eating breakfast), perceived modeling by parents and friends, and intention were measured using five point Likert scales $(-2$ to +2$)$, (Table 1 ). Attitude was the only construct assessed with two items and a mean score was used (Chronbach $\alpha=0.80$ ). Missing data was imputed for the TPB questions using the median score $(\sim 6.8 \%$ of the TPB scores were imputed). Due to non normal distribution, the TPB variables were dichotomized using a median split $(0=$ weaker; $1=$ stronger $)$.

The questions pertaining to the environmental factors are listed in Table 1. Physical availability was measured with one item. The political environment was measured with three yes $(=1)$ and no $(=0)$ questions and a composite score ranging from 0 to 3 rules was computed using a total summed score. Socio-cultural environment was measured using three separate questions regarding family meal patterns: eating breakfast with a parent, eating the evening meal with a parent, eating the evening meal with TV.

Demographic data was collected through the YMR self reported surveys. Age was calculated using the date of birth and the date of the questionnaire assessment. Children indicated in which country they and both their parents had been born, and were divided into two categories: "Western descent"-defined as the student or one or both parents born in Europe, North America, Indonesia, Japan or Oceania and "non-Western descent"-defined as the student or one or both parents born in a country other then the aforementioned countries. Schools provided the education level of the child (university preparation, higher professional preparation, or vocational preparation).

\section{Statistical analysis}

Descriptive and frequency analysis of the demographic, TPB and environmental variables was done using SPSS 15.0. Multi-level multiple logistic regression analyses were preformed to examine the direct and indirect associations between individual cognitions and environmental factors and daily breakfast consumption in MLwiN version 2.02. A two level random intercept model (children clustered within schools) was used. A random intercept model (null model) without explanatory variables was fitted first to determine the significance of the between school variance using the standard error obtained from a second order predicted quasi-likelihood estimation. Subsequently, the independent variables were entered in blocks. Demographic variables were entered in block one, the environmental variables directly concerning breakfast consumption in block two (political, physical availability, breakfast with parent), all environmental variables in block three (political, physical availability, breakfast with parent, evening meal with parent, evening meal in front of
TV), and the TPB variables were analyzed separately in block four, see Table 4.

To study the TPB variables as potential mediators of the association between the environment and breakfast consumption we used the difference in coefficients approach and determined significant mediation when the percentage change in odds ratio between adjusted and unadjusted models was $>20 \%$ (Mackinnon et al., 2002). This was done by 1) regressing the independent variables (breakfast with parent, political, physical availability) onto the outcome; 2) adding the group of significant TPB variables (attitude, decision for self, friend modeling, parent modeling, intention) to the previous model; and 3) calculating the change in the odds ratio of the environmental factors between the two models. Our analysis did not include the evening meal environmental variables as they theoreti-

Table 3

Behavioral, environmental and cognitive characteristics of the study population $(n=1089)$ from The Netherlands, 2005-2006

\begin{tabular}{|c|c|c|}
\hline Characteristics & $N$ & $\%$ \\
\hline \multicolumn{3}{|l|}{ Total breakfast consumption ${ }^{\mathrm{a}}$} \\
\hline Everyday & 614 & 56.4 \\
\hline \multicolumn{3}{|l|}{ Attitude $\mathrm{b}^{\mathrm{b}}$} \\
\hline Strong & 855 & 78.5 \\
\hline \multicolumn{3}{|l|}{ Subjective norm ${ }^{\mathrm{b}}$} \\
\hline Strong & 676 & 62.1 \\
\hline \multicolumn{3}{|l|}{ Parent modeling ${ }^{\mathrm{b}}$} \\
\hline Strong & 735 & 66.6 \\
\hline \multicolumn{3}{|l|}{ Friend modeling ${ }^{\mathrm{b}}$} \\
\hline Strong & 753 & 69.1 \\
\hline \multicolumn{3}{|c|}{ Perceived behavior control 1: decide for oneself ${ }^{b}$} \\
\hline Strong & 629 & 57.8 \\
\hline \multicolumn{3}{|c|}{ Perceived behavior control 2: ease of eating breakfast ${ }^{\mathrm{b}}$} \\
\hline Strong & 655 & 60.1 \\
\hline \multicolumn{3}{|c|}{ Intention: breakfast consumption in the next 6 months ${ }^{\mathrm{b}}$} \\
\hline Strong & 712 & 65.4 \\
\hline \multicolumn{3}{|c|}{ Political score: rules regarding breakfast eating ${ }^{c}$} \\
\hline 0 rules & 392 & 36.0 \\
\hline 1 rule & 337 & 30.9 \\
\hline 2 rules & 220 & 20.2 \\
\hline 3 rules & 140 & 12.9 \\
\hline \multicolumn{3}{|l|}{ Physical availability } \\
\hline Yes & 1017 & 93.4 \\
\hline \multicolumn{3}{|c|}{ Frequency of eating breakfast with parent } \\
\hline None/rarely (0-2 d/week) & 585 & 53.7 \\
\hline Sometimes (2.5-4.5 d/week) & 162 & 14.9 \\
\hline Frequently (5-6.5 d/week) & 106 & 9.7 \\
\hline Everyday (7 days/week) & 236 & 21.7 \\
\hline \multicolumn{3}{|c|}{ Frequency of eating evening meal with parent } \\
\hline None/rarely (0-2 d/week) & 122 & 11.2 \\
\hline Sometimes (2.5-4.5 d/week) & 109 & 10.0 \\
\hline Frequently (5-6.5 d/week) & 147 & 13.5 \\
\hline Everyday (7 days/week) & 711 & 65.3 \\
\hline \multicolumn{3}{|c|}{ Frequency of eating evening meal with TV } \\
\hline None/rarely (0-2 d/week) & 603 & 55.4 \\
\hline Sometimes (2.5-4.5 d/week) & 161 & 14.8 \\
\hline Frequently (5-6.5 d/week) & 65 & 6.0 \\
\hline Everyday (7 days/week) & 260 & 23.9 \\
\hline
\end{tabular}

a The outcome variable was dichotomized using children who ate breakfast everyday (1) verses those who did not eat breakfast everyday (0).

b A 5 point Likert scale -2 (weakest) to +2 (strongest) was used. The variable was significantly skewed and dichotomized using median split. The reference categories for the dichotomized variables are listed.

Political sum score represents the total number of rules the child reported. 
cally would not cause a shift in the cognitive influence on breakfast consumption.

\section{Results}

The sample consisted of $53.7 \%$ males, the average age of the respondents was 14 years, and the sample was 51\% Western descent (see Table 2). Mean breakfast consumption was 5.5 days per week. See Table 3 for the distribution of the respondents.

Table 4 presents the results of the multilevel multiple logistic regression analyses. Significant between-school variance was found in the null model (variance $=0.32(0.12,0.52))$. Once the demographics were adjusted for, the between school variance was no longer significant $($ variance $=0.08(-0.06,0.21))$.

All of the environmental correlates were associated with daily breakfast consumption (see Table 4, "Breakfast Environment model" and "Total Environment model" for odds ratios). Having two breakfast rules, having sufficient breakfast products available, having breakfast with a parent frequently or always, or always having the evening meal with a parent significantly increased the odds of eating breakfast daily compared to the reference category. Children who ate dinner in front of the TV sometimes, frequently or always had significantly decreased odds of having breakfast everyday compared to those who did so rarely.
Attitude, parental modeling, friend modeling, decision for self and intention were significantly associated with daily breakfast consumption (see Table 4, "Cognitions model"). Children with stronger attitudes, with stronger modeling from parents and friends, and who had stronger intention were significantly more likely to eat breakfast daily. Children who decided for themselves to eat breakfast compared to those who didn't decide for themselves had decreased odds of daily breakfast consumption.

In the mediation model (see Table 4, "Mediation model"), the odds ratio for the political environment 2 rules compared to zero dropped by $30.0 \%$, physical availability dropped by $20.0 \%$, and the odds ratio of frequently and always having breakfast with a parent dropped by $28.5 \%$ and $42.2 \%$ respectively.

\section{Discussion}

This study has shown that a child's cognitions and the home environment significantly affect the probability of daily adolescent breakfast consumption. A child's attitude, perceived behavioral control (decision for self), modeling by friends and parents, and intention were significant correlates of daily breakfast consumption. The environmental factors eating breakfast with a parent, political (parental rules regarding breakfast), and physical availability were

Table 4

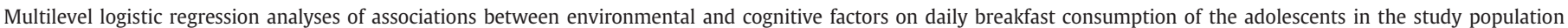
$(n=1089)$ from the Netherlands, 2005-2006

\begin{tabular}{|c|c|c|c|c|c|c|}
\hline & Null model & Demographics model & $\begin{array}{l}\text { Breakfast environment } \\
\text { model }\end{array}$ & $\begin{array}{l}\text { Total environment } \\
\text { model }\end{array}$ & Cognitions model & Mediation model \\
\hline Predicted & & $62 \%$ & $69 \%$ & $71 \%$ & $78 \%$ & $80 \%$ \\
\hline Gender (boys) & & $0.94(0.73,1.21)$ & $0.57(0.43,0.75)$ & $0.52(0.39,0.69)$ & $0.74(0.54,1.01)$ & $0.73(0.53,1.02)$ \\
\hline Age & & $0.86(0.77,0.97)$ & $0.95(0.84,1.08)$ & $.96(0.85,1.09)$ & $0.91(0.79,1.04)$ & $0.93(0.80,1.08)$ \\
\hline \multicolumn{7}{|l|}{ School level } \\
\hline University preparation & & 1.00 & 1.00 & 1.00 & & 1.00 \\
\hline Higher professional preparation & & $0.55(0.36,0.86)$ & $0.93(0.58,1.49)$ & $0.53(0.33,0.86)$ & $0.64(0.37,1.10)$ & $0.62(0.35,1.09)$ \\
\hline Vocational preparation & & $0.59(0.43,0.81)$ & $0.55(0.78,0.39)$ & $0.57(0.40,0.81)$ & $0.67(0.45,0.99)$ & $0.63(0.42,0.96)$ \\
\hline Ethnicity (Western born) & & $0.58(0.44,0.75)$ & $0.55(0.41,0.73)$ & $0.68(0.50,0.92)$ & $0.57(0.41,0.79)$ & $0.54(0.38,0.75)$ \\
\hline \multicolumn{7}{|l|}{ Political } \\
\hline 0 rules & & & 1.00 & 1.00 & & 1.00 \\
\hline 1 rule & & & $1,14(0.83,1.58)$ & $1.07(0.77,1.50)$ & & $0.93(0.63,1.37)$ \\
\hline 2 rules $^{\mathrm{a}}$ & & & $2.04(1.39,3.00)$ & $1.87(1.26,2.77)$ & & $1.43(0.90,2.29)$ \\
\hline 3 rules & & & $1.40(0.87,2.25)$ & $1.32(0.81,2.14)$ & & $0.87(0.50,1.53)$ \\
\hline Physical availability & & & $1.99(1.15,3.45)$ & $1.85(1.05,3.26)$ & & $1.60(0.84,3.05)$ \\
\hline \multicolumn{7}{|l|}{ Breakfast with parent } \\
\hline Rarely & & & 1.00 & 1.00 & & 1.00 \\
\hline Sometimes & & & $1.49(1.02,2.18)$ & $1.45(0.98,2.14)$ & & $1.15(0.74,1.79)$ \\
\hline Frequently & & & $2.70(1.64,4.45)$ & $2.64(1.58,4.39)$ & & $1.93(1.09,3.43)$ \\
\hline Always & & & $5.29(3.55,7.88)$ & $4.58(3.04,6.91)$ & & $3.06(1.93,4.84)$ \\
\hline \multicolumn{7}{|l|}{ Evening meal with parent } \\
\hline Rarely & & & & 1.00 & & \\
\hline Sometimes & & & & $1.01(0.56,1.83)$ & & \\
\hline Frequently & & & & $0.80(0.46,1.41)$ & & \\
\hline Always & & & & $1.74(1.09,2.77)$ & & \\
\hline \multicolumn{7}{|l|}{ Evening meal with TV } \\
\hline Rarely & & & & 1.00 & & \\
\hline Sometimes & & & & $0.65(0.43,0.97)$ & & \\
\hline Frequently & & & & $0.49(0.27,0.87)$ & & \\
\hline Always & & & & $0.57(0.41,0.81)$ & & \\
\hline Attitude & & & & & $2.55(1.66,3.94)$ & $2.39(1.54,3.71)$ \\
\hline Subjective norm & & & & & $0.81(0.56,1.16)$ & \\
\hline Parent modeling & & & & & $2.47(1.75,3.50)$ & $2.14(1.52,3.00)$ \\
\hline Friend modeling & & & & & $1.95(1.39,2.73)$ & $1.86(1.31,2.65)$ \\
\hline Decision for self & & & & & $0.59(0.42,0.82)$ & $0.67(0.47,0.95)$ \\
\hline Ease of breakfast eating & & & & & $1.42(0.98,2.04)$ & \\
\hline Intention & & & & & $6.22(4.25,9.12)$ & $6.10(4.22,8.82)$ \\
\hline \multicolumn{7}{|l|}{ Random effects } \\
\hline Between school variance (se) ${ }^{\mathrm{b}}$ & $0.321(0.104)$ & $0.076(0.069)$ & $0.090(.079)$ & $0.088(.081)$ & $0.109(0.100)$ & $0.170(0.115)$ \\
\hline
\end{tabular}

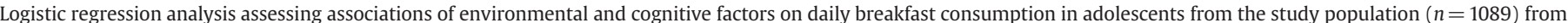
Rotterdam, The Netherlands during the 2005-2006 school year. Reference values italicized. Bolded values indicate significant results $0.0001<p<0.05$.

a Most common two rules were: Are there rules about- "whether you should eat breakfast?"; "what you are allowed and not allowed to eat for breakfast?"

b Multilevel results indicate clustering at the school level was significant when $95 \%$ confidence interval of between-school variances is $>0$. 
associated with adolescent breakfast consumption and these associations were partly mediated by the child's cognitions.

In line with the findings of previous studies (Cusatis and Shannon, 1996; Gummeson et al., 1997; Berg et al., 2000; Brown and Ogden, 2004; Martens et al., 2005) we found intention, attitude and parental modeling to have the strongest association with daily breakfast consumption. New findings of this study include the positive association of friend modeling and the negative association of perceived behavioral control (decision making power) with breakfast consumption. According to the TPB, a higher perceived behavior control is associated with a higher intention and increased likelihood of performing a behavior. One explanation of our finding may be that the perceived behavior control construct actually measured a concept other than control. Alternatively, previous works on parenting style and diet have shown that the aspect of control is important. Parents who exert control over their child's diet can affect the child's intake of healthy and unhealthy snacks and girls who are more socially independent eat breakfast less frequently then girls who are not as socially independent (Brown and Shannon, 2004; Brown et al., 2008). Accordingly, parental rules and control over the decision to eat breakfast may be beneficial to improving breakfast consumption by adolescents.

The associations of the political (parental rules), the socio-cultural (family meals), and the physical (availability) environment with adolescent breakfast consumption had a direct and an indirect effect on breakfast consumption. Only a small proportion of the effect of the physical environment on breakfast consumption was mediated, indicating that the association of the physical environment on breakfast consumption is mainly direct. Indeed, if there is food available it may positively affect one's cognitions, yet if there were no breakfast products available, one cannot eat the meal despite positive cognitions. Interestingly, the non-linear association we found with the political environment (rules) could be because not all of the rules measured were equally influential on breakfast consumption and further investigation regarding which parental rules are most influential to adolescent diet habits is warranted.

This study suggests that parents have an important influence over their child's breakfast consumption. A child's cognitions towards breakfast consumption are partly shaped by the home environment and all of the environmental factors included in this study were primarily influenced by parents: parents are responsible for the availability of foods, setting the rules, and initiating family meal patterns. Parents also serve as important role models and influence the perceived control a child has over the decision to eat breakfast. Therefore, interventions to increase adolescent breakfast consumption should address parental breakfast consumption, as well as the underlying mechanisms that lead to family meal patterns, rules and modeling-such as parenting styles and practices.

The EnRG model proved to be a useful tool in conceptualizing the pathways for our mediation analysis. However, there can be debate about whether a factor should be regarded as environmental or as an individual cognition. This study regarded parental rules as a factor in the political environment, but it could also be regarded as the sociocultural environment. We defined modeling as a cognition, and perceived family meal patterns as a socio-cultural environmental factor, whereas both concepts were defined as cognitions in previous work (Berg et al., 2000; Tibbs et al., 2001; Kvaavik et al., 2005; Martens et al., 2005). Nonetheless, different categorizations of these concepts would not have resulted in other findings.

Limitations of this study include its cross-sectional design, which makes it impossible to derive causation. Although a common procedure in dietary research, contributing determinants and behavior data were collected in one single self-reported survey, making it susceptible to misclassification bias. Additionally, those less likely to be dropped from the study were from higher school levels, female, and of Western descent which may effect generalizability.

\section{Conclusions}

In conclusion, this study shows that an adolescent's cognitions and environmental factors are associated with eating breakfast daily. An adolescent's intention, attitude, perceived behavioral control, and modeling by important others are significant correlates associated with breakfast consumption. Additionally, a supportive home environment, which is largely created by parents, is associated with adolescent breakfast consumption both directly and indirectly. Therefore, addressing parents in future interventions aimed at improving adolescent breakfast consumption is essential. Targeting parents should include raising awareness that providing rules, breakfast products, positive family meal patterns, and being a good role model is influential, even for teenagers!

\section{Conflict of interest statement}

The authors declare that they have no conflicts of interest.

\section{Acknowledgments}

This study was financially supported by a grant from ZonMw, The Netherlands Organization for Health Research and Development (grant ID no 2100.0103).

\section{References}

Affenito, S.G., Thompson, D.R., Barton, B.A., et al., 2005. Breakfast consumption by African-American and white adolescent girls correlates positively with calcium and fiber intake and negatively with body mass index. J. Am. Diet. Assoc. 105, 938-945.

Ajzen, I., 1991. The theory of planned behavior. Organ. Behav. Hum. Decis. Process 50, $179-211$.

Bandura, A., 1971. Psychological Modeling: Conflicting Theories. Transaction Publishers, New Brunswick, N.J.

Barlow, S.E., 2007. Expert committee recommendations regarding the prevention, assessment, and treatment of child and adolescent overweight and obesity: summary report. Pediatrics Suppl. 4, S164-S192.

Berg, C., Jonsson, I., Conner, M., 2000. Understanding choice of milk and bread for breakfast among Swedish children aged 11-15 years: an application of the theory of planned behaviour. Appetite 34, 5-19.

Brown, R., Ogden, J., 2004. Children's eating attitudes and behavior: a study of the modeling and control theories of parental influence. Health Educ. Res. 19, 261-271.

Brown, K., Ogden, J., Vogele, C., Gibson, L., 2008. The role of parental control practices in explaining children's diet and BMI. Appetite 50, 252-259.

Crossman, A., Sullivan, A., Benin, M., 2006. The family environment and American adolescents' risk of obesity as young adults. Soc. Sci. Med. 63, 2255-2267.

Cusatis, D.C., Shannon, B.M., 1996. Influences on adolescent eating behavior. J. Adolesc. Health 18, 27-34.

Gummeson, L., Jonsson, I., Conner, M., 1997. Predicting Intentions of behavior of Swedish 10-16 year olds at breakfast. Food Qual. Pref. 8, 297-306.

Keski-Rahkonen, A., Kaprio, J., Rissanen, A., Virkkunen, M., Rose, R.J., 2003. Breakfast skipping and health-compromising behaviors in adolescents and adults. Eur. J. Clin. Nutr. 57, 842-853.

Koplan, J., Liverman, C., Kraak, V., 2005. Preventing childhood obesity: health in the balance: executive summary. J. Am. Diet. Assoc. 105, 131-138.

Kremers, S.P., de Bruijn, G.J., Visscher, T.L., van Mechelen, W., de Vries, N.K., Brug, J. 2006. Environmental influences on energy balance-related behaviors: a dualprocess view. Int. J. Behav. Nutr. Phys. Act 3, 9-19.

Kvaavik, E., Lien, N., Tell, G.S., Klepp, K., 2005. Psychosocial predictors of eating habits among adults in their mid-30s: the Oslo Youth Study follow-up 1991-1999. Int. J. Behav. Nutr. Phys. Act 2, 9-20.

Larson, N.I., Neumark-Sztainer, D., Hannan, P.J., Story, M., 2007. Family meals during adolescence are associated with higher diet quality and healthful meal patterns during young adulthood. J. Am. Diet. Assoc. 107, 1502-1510.

Martens, M.K., van Assema, P., Brug, J., 2005. Why do adolescents eat what they eat? Personal and social environmental predictors of fruit, snack and breakfast consumption among 12-14-year-old Dutch students. Public Health Nutr. 8, 1258-1265.

Mackinnon, D., Lockwood, C., Hoffman, J., West, S., Sheets, V., 2002. A comparison of methods to test mediation and other intervening variable effects. Psychol. Methods 7, 83-104.

Niemeier, H.M., Raynor, H.A., Lloyd-Richardson, E.E., Rogers, M.L., Wing, R.R., 2006. Fast food consumption and breakfast skipping: predictors of weight gain from adolescence to adulthood in a nationally representative sample. J. Adolesc. Health 39, 842-849.

Rampersaud, G.C. Pereira, M.A., Girard, B.L., Adams, J., Metzl, J.D., 2005. Breakfast habits, nutritional status, body weight, and academic performance in children and adolescents. J. Am. Diet. Assoc. 105, 743-760.

Roseman, M.G., Yeung, W.K., Nickelsen, J., 2007. Examination of weight status and dietary behaviors of middle school students in Kentucky. J. Am. Diet. Assoc. 107, 1139-1145. 
Swinburn, B.A., Egger, G., Raza, F., 1999. Dissecting obesogenic environments: the development and application of a framework for identifying and prioritizing environmental interventions for obesity. Prev. Med. 29, 563-570.

Swinburn, B.A., Caterson, I., Seidell, J.C., James, W.P., 2004. Diet, nutrition and the prevention of excess weight gain and obesity. Public Health Nutr. 7, 123-146.

Tibbs, T., Haire-Joshu, D., Schechtman, K.B., et al., 2001. The relationship between parental modeling, eating patterns, and dietary intake among African-American parents. J. Am. Diet. Assoc. 101, 535-541.
Utter, J., Scragg, R., Mhurchu, C.N., Schaaf, D., 2007. At-home breakfast consumption among New Zealand children: associations with body mass index and related nutrition behaviors. J. Am. Diet. Assoc. 107, 570-576.

van der Horst, K., Oenema, A., van de Looij-Jansen, P., Brug, J., 2008. The ENDORSE study: research into environmental determinants of obesity related behaviors in Rotterdam schoolchildren. BMC Public Health, 8:142. Published online 2008 April 28. doi: 10.1186/1471-2458-8-142. PMCID: PMC2413223.

Videon, T.M., Manning, C.K., 2003. Influences on adolescent eating patterns: the importance of family meals. J. Adolesc. Health 32, 365-373. 